\title{
Cegah Diabetes Melitus Tipe 2 Dengan "Sedia-Ubayahi" (Senam Diabetik \& Ubah Gaya Hidup)
}

\author{
Lenny Rosbi Rimbun ${ }^{a}$, Yudha Anggit Jiwantoro ${ }^{\text {, }}$, Maryatic \\ ${ }^{a}$ STIKES Pertamedika, Bekasi Barat, Jawa Barat, 17133, Indonesia

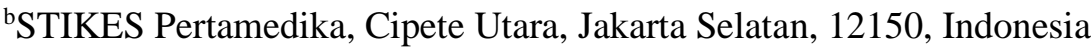 \\ 'STIKES Pertamedika, Depok, Jawa Barat, 16515, Indonesia \\ e-mail korespondensi: yudhaanggitj@gmail.com
}

\begin{abstract}
Diabetes mellitus is a disease characterized by high blood sugar levels. Basically, this happens because the body lacks the hormone insulin produced by the pancreas gland. It is therefore important to achieve and maintain metabolic control to prevent an increased risk of microvascular and macrovascular complications and lack of glycemic control. The purpose of this study is to analyze the effect of diabetes exercise therapy and lifestyle on blood sugar levels. Pre-experimental research design which is a research design that tests interventions in groups without involving control variables. The research design uses one postest postest design. The sample of the study were 40 respondents who met the inclusion and exclusion criteria. Test analysis using paired t test. The results showed that there was an influence of diabetes exercises and lifestyle (diet and activity) on blood sugar levels with a value of $p$ (0,000). The conclusion that diabetic exercise and changing a healthy lifestyle can significantly control blood sugar levels.
\end{abstract}

Keywords: type II diabetes melitus, diabetic gymnastics, lifestyle

\begin{abstract}
Abstrak
Diabetes melitus merupakan penyakit yang ditandai tingginya kadar gula dalam darah. Pada dasarnya, hal ini terjadi karena tubuh kekurangan hormon insulin yang diproduksi oleh kelenjar pankreas. Oleh karena itu penting untuk mencapai dan mempertahankan kontrol metabolik untuk mencegah peningkatan risiko komplikasi mikrovaskuler dan makrovaskuler dan kurangnya kontrol glikemik. Tujuan penelitian ini menganalisis pengaruh terapi senam diabetes dan gaya hidup terhadap kadar gula darah. Desain penelitian pra-eksperimen yang merupakan desain penelitian yang menguji intervensi dalam kelompok tanpa melibatkan variabel kontrol. Desain penelitian menggunakan one postest postest design. Sampel penelitian adalah responden yang memenuhi kriteria inklusi dan eksklusi sebanyak 40 warga. Analisa uji menggunakan paired t test. Hasil penelitian menunjukkan bahwa ada pengaruh senam diabetes dan gaya hidup (pola makan dan aktivitas) terhadap kadar gula darah dengan nilai p $(0,000)$. Kesimpulan bahwa senam diabetik dan mengubah gaya hidup yang sehat dapat mengontrol kadar gula dalam darah secara signifikan.
\end{abstract}

Kata kunci: diabetes tipe II, senam diabetik, gaya hidup

\section{PENDAHULUAN}

Penyakit degeneratif yang dapat timbul dikarenakan pola dan gaya hidup yang dapat mengganggu kesehatan seseorang adalah Diabetes Melitus tipe 2 (Islaeli et al., 2019). Diabetes Melitus (DM) didefinisikan sebagai suatu kelompok penyakit metabolik dengan karakteristik hiperglikemia kronis yang terjadi karena kelainan sekresi insulin, kerusakan kinerja insulin atau kombinasi keduanya. Ketidakoptimalnya kerja insulin merupakan akibat dari kurangnya sekresi insulin atau kurangnya respon jaringan terhadap insulin. Kurangnya sekresi insulin dan kerusakan kerja insulin sering terjadi bersamaan sehingga menyebabkan kelainan yang merupakan penyebab terjadinya hiperglikemia (American Diabetes Association, 2015)

Diabetes tipe 2 terjadi pada saat organ pankreas dalam tubuh penderita tidak memproduksi relatif cukup insulin untuk mempertahankan kadar gula darah dalam batas normal. Penyebab lainnya adalah selsel tubuh yang menjadi kurang peka terhadap insulin atau yang dikenal dengan 
istilah resistensi terhadap insulin. Kadar gula darah biasanya dikendalikan oleh hormon insulin yang diproduksi oleh pankreas. Insulin berfungsi untuk memindahkan gula dari darah ke sel-sel tubuh yang akan mengubahnya menjadi energi (Sutrisno, 2008).

Hasil penelitian Riskesdas (Riset Kesehatan Dasar) dari Kementrian Kesehatan Indonesia pada tahun 2013, sekitar 12 juta penduduk Indonesia yang berusia di atas 15 tahun menderita diabetes tipe 2. Ini berarti 6,9 persen dari total penduduk usia di atas 15 tahun. Tapi hanya 26 persen saja yang sudah terdiagnosis, sedangkan sisanya tidak menyadari dirinya sebagai penderita diabetes tipe 2 (Waspadji, 2009).

Penyakit ini membunuh 3,8 juta orang per tahun dan dalam setiap 10 detik seorang penderita akan meninggal karena sebab-sebab yang terkait dengan diabetes. Komplikasi yang paling memungkinkan dari diabetes yang tidak teratasi, baik itu tipe 1 atau tipe 2, adalah nekrosis, yang akan membuat lumpuh. Tanpa perawatan dan manajemen yang tepat, sel tubuh tidak akan mampu untuk menggunakan glukosa di dalam aliran darah dan akan mati secara perlahan (IDF, 2014).

Sangat penting untuk mencapai dan mempertahankan kontrol metabolik pada anak dan remaja untuk mencegah peningkatan risiko komplikasi mikrovaskuler dan makrovaskuler dan kurangnya kontrol glikemik pada saat dewasa (Perkeni, 2006).

Kegiatan fisik secara teratur terbukti mengurangi sejumlah faktor-faktor risiko aterogenik, misalkan membantu mengurangi obesitas dan menurunkan tekanan darah serta memperbaiki kesensitifan insulin. Toleransi glukosa memiliki hubungan positif dengan aktifitas fisik total, aktifitas fisik sedang dan aktifitas fisik ringan selama 5 menit (Shahab, 2009).

Senam diabetes adalah senam fisik yang dirancang menurut usia dan status fisik dan merupakan bagian dari pengobatan diabetes mellitus. Senam diabetes tidak sama dengan senam normal biasanya, bedanya terletak pada tujuannya yaitu mengurangi gula darah kotor dan kelebihan konsumsi karbohidrat di dalam tubuh.

Pada penelitian Iche Andriyani Liberty, diperoleh 196 responden, terdiri dari 98 kasus yakni wanita prediabetes dan 98 kontrol yakni wanita dengan normoglikemik. Hasil analisa menunjukkan dari kelima variabel yakni tingkat pendidikan, pekerjaan, status marital, riwayat keluarga, dan obesitas, terdapat tiga variabel yang memiliki hubungan yang signifikan dengan kejadian prediabetes yakni tingkat pendidikan, status marital, dan obesitas.Sedangkan pada analisa multivariat terdapat dua variabel yakni status marital $(\mathrm{OR}=3,87 \mathrm{CI}$ $95 \%=1,98-7,60 \mathrm{p}$ value $=0,00)$ dan obesitas $(\mathrm{OR}=2,63$ CI 95\%=1,36 - 5,35 p value $=0,05$ ) yang memiliki hubungan yang signifikan dengan kejadian prediabetes (Liberty, 2016).

\section{METODE}

Peneliti menggunakan desain pre experiment dengan rancangan one group pretest postest design, efektivitas perlakuan dinilai dengan cara membandingkan nilai pre test dengan post test (Jiwantoro, 2017). Sampel penelitian ini adalah warga RW 09 Kebayoran Lama dengan penyakit diabetes melitus tipe II yang memenuhi kriteria inklusi sebanyak 40 warga. Adapun kriteria inklusi penelitian sebagai berikut 1) Warga dengan DM tipe II atau yang memiliki orangtua dengan DM. 2) Bersedia mengikuti proses penelitian dari awal sampai akhir. 3) Mampu membaca dan menulis (mengisi kuesioner yang telah diuji coba dengan nilai $r$ hitung $>0,444$ (20 sampel) dengan cronbach alpha 0,900 dan 0,921 .

Alur penelitian dimulai dengan pengukuran kadar gula sebanyak 2 kali, yaitu sebelum intervensi senam diabetes sebanyak 3 kali, setelah itu dilakukan pengukuran ulang kadar gula. Sedangkan 
intervensi senam diabetik dilakukan seminggu 3 kali dengan durasi 30 menit. Interval pelaksanaan selama 1 bulan Analisa uji menggunakan paired $t$ test, karena data berdistribusi normal.

Perubahan gaya hidup dilakukan dengan pemberian pendidikan kesehatan dan pendampingan (datang secara acak ke rumah responden, seminggu 2 kali). Pengukuran gaya hidup yang terdiri dari pola makan dan aktivitas, dilakukan dengan instrumen kuesioner sebanyak 20 pertanyaan. Kuesioner sebelumnya sudah dilakukan uji validitas dan reliabilitas. Pemberian kuesioner dilakukan 2 kali, yaitu sebelum pemberian penyuluhan dan setelah saat penutupan penelitian. Analisa uji menggunakan paired $t$ test untuk menentukan ada tidaknya perubahan gaya hidup pada responden setelah diberi informasi penyuluhan kesehatan. Penelitian ini sudah lolos uji etik penelitian di LPPM Stikes Pertamedika pada bulan 14 Agustus 2017.

\section{HASIL}

Tabel 1. Analisis Kadar gula darah sebelum dan setelah senam diabetik pada responden di Kebayoran Lama Jakarta Selatan

\begin{tabular}{ccccc}
\hline No & Gula Darah & Mean & $\begin{array}{c}p \\
\text { value }\end{array}$ & $\begin{array}{c}\mathrm{T} \\
\text { hitung }\end{array}$ \\
\cline { 1 - 3 } 1 & Pre & 205.10 & & \\
\cline { 1 - 3 } 2 & Post & 145.95 & & 4.4660 \\
\hline & Selisih & 59.150 & & \\
\hline
\end{tabular}

Sumber: data primer

Hasil tabel 1, terdapat perbedaan ratarata antara sebelum dan setelah pemberian intervensi. Mean kadar gula darah sebelum $(205,10)$, sedangkan setelah intervensi $(145,95)$. Selisih perbedaan mean keduanya $(59,150)$. Hasil analisis uji paired $t$ test didapatkan nilai $\mathrm{p}$ value $(0,000)$ dengan t hitung (4.466), p value < 0,05 maka menunjukkan ada pengaruh pemberian senam diabetes melitus pada responden terhadap kadar gula darah.
Tabel 2. Analisis pola makan sebelum dan setelah pendidikan kesehatan pada responden di Kebayoran Lama Jakarta Selatan

\begin{tabular}{ccccc}
\hline No & Pola Makan & Mean & P value & T hitung \\
\cline { 1 - 3 } 1 & Pre & 8.40 & & \\
\cline { 1 - 3 } 2 & Post & 9.30 & & -4.949 \\
\cline { 1 - 3 } & Selisih & -0.90 & & \\
\hline
\end{tabular}

Sumber: data primer

Hasil tabel 2, terdapat perbedaan mean antara sebelum dan setelah pemberian intervensi. Mean pola makan sebelum intervensi (8.40), sedangkan setelah intervensi (9.30). Selisih perbedaan mean keduanya $(-0,90)$. Tanda (-) menunjukkan bahwa nilai pre lebih rendah dibandingkan nilai post. Hasil analisis uji paired t test didapatkan nilai $\mathrm{p}$ value $(0,000)$ dengan $\mathrm{t}$ hitung (-4.949), $\mathrm{p}$ value $<0,05$ maka menunjukkan ada pengaruh pemberian penyuluhan gaya hidup terhadap perubahan pola makan pada responden.

Tabel 3. Analisis aktivitas fisik sebelum dan setelah pendidikan kesehatan pada responden di Kebayoran Lama Jakarta Selatan

\begin{tabular}{ccccc}
\hline No & Aktivitas & Mean & $p$ value & T hitung \\
\hline 1 & Pre & 9,68 & & \\
\cline { 1 - 2 } 2 & Post & 12,63 & & $-12,154$ \\
\hline & Selisih & $-2,950$ & & \\
\hline
\end{tabular}

Sumber: data primer

Hasil tabel 4, terdapat perbedaan mean antara sebelum dan setelah pemberian intervensi. Mean aktivitas sebelum intervensi (9.68), sedangkan setelah intervensi (12.63). Selisih perbedaan mean keduanya (-2.950). Tanda (-) menunjukkan bahwa nilai pre lebih rendah dibandingkan nilai post. Hasil analisis uji paired t test didapatkan nilai $\mathrm{p}$ value $(0,000)$ dengan $\mathrm{t}$ hitung (-12.154), $\mathrm{p}$ value $<0,05$ maka 
menunjukkan ada pengaruh pemberian penyuluhan gaya hidup terhadap perubahan aktivitas pada responden.

\section{PEMBAHASAN}

Hasil penelitian ini dapat dilihat bahwa terdapat perbedaan mean antara sebelum dan setelah pemberian intervensi. Hal tersebut menunjukkan bahwa sebelum dilakukan senam diabetes, sebagian besar responden dengan kadar gula darah yang tinggi dengan rata-rata $(205,10 \mathrm{gr} / \mathrm{dl})$, sedangkan setelah mengikuti senam diabetes selama 3 kali terjadi penurunan rata-rata kadar gula darah yaitu menjadi $(145,95 \mathrm{gr} / \mathrm{dl})$. Perbedaan rata-rata keduanya sebesar $(59,150 \mathrm{gr} / \mathrm{dl})$ atau dapat diartikan bahwa dengan senam diebetes rutin 3 kali mampu menurunkan kadar gula darah secara siginifikan $59 \mathrm{gr} / \mathrm{dl}$. Selain itu dari hasil analisis uji paired $t$ test didapatkan nilai $\mathrm{p}$ value $(0,000)$ dengan $\mathrm{t}$ hitung (4.466), artinya nilai $\mathrm{p}$ value $\leq 0,05$ maka menunjukkan ada pengaruh pemberian senam diabetes melitus pada responden terhadap kadar gula darah.

Hasil penelitian Erlina menunjukkan senam diabetes berpengaruh terhadap kadar glukosa darah pasien DM tipe 2 $(\mathrm{P}=0,006)$. Stres menunjukkan hubungan yang kuat dengan kadar glukosa darah sebelum intervensi $(\mathrm{r}=0,688, \mathrm{P}=0,005)$. Stres menunjukkan hubungan yang kuat dengan kadar glukosa darah sesudah intervensi $(r=0,575, P=0,025)$. Hubungan berpola positif. Penggunaan $\mathrm{OHO}$ tidak berhubungan dengan kadar glukosa darah sebelum intervensi $(\mathrm{P}=0,285)$. Penggunaan $\mathrm{OHO}$ berhubungan dengan kadar glukosa darah sesudah intervensi $(\mathrm{P}=0,002)$.(Erlina, 2010).

Penanganan diabetes berfokus pada mengontrol kadar gula darah (glukosa). Hal tersebut dapat dijalankan dengan memperhatikan pola makan dan aktivitas, serta merubah gaya hidup yang tidak mendukung program diabetes. Para ahli mengatakan bahwa penderita diabetes harus menjaga dan mengontrol berat badan, karena menurunkan berat badan sebanyak $5-10 \%$ akan menurunkan kadar gula darah secara signifikan.

Karbohidrat memberikan pengaruh besar terhadap kadar gula dalam darah. Bukan berarti penderita diabetes harus menghindari karbohidrat sama sekali, melainkan cermat dalam memilih jenis karbohidrat yang dikonsumsi. Secara umum, dianjurkan untuk mengkonsumsi karbohidrat kompleks dan berserat tinggi, karena akan lebih lambat diuraikan oleh pencernaan sehingga membantu menjaga level gula darah. Selain itu, karbohidrat kompleks akan memberikan energi lebih bagi tubuh dan membuat kita merasa kenyang lebih lama.

Hasil penelitian ini menunjukkan bahwa pada pemberian pendidikan kesehatan terkait gaya hidup yang baik pada diabetes melitus tipe II mampu merubah mindset responden dan keluarga bahwa DM dapat dikontrol dengan cara mengatur pola makan dan aktivitas yang benar. Hasil analisis uji paired $t$ test didapatkan nilai $\mathrm{p}$ value $0,000 \leq 0,05$, artinya ada pengaruh pendidikan kesehatan terhadap perubahan pola makan dan aktivitas pasien DM, yang sebelumnya tidak mengetahui menu makanan yang benar, kapan harus makan, apa yang dianjurkan, kini responden tahu dan mulai menerapkan dalam kehidupan sehari-hari.

Hasil penelitian Nur Astuti menunjukkan bahwa ada pengaruh pendidikan kesehatan terhadap perbedaan nilai pre-test dan post-test pengetahuan $(\mathrm{p}=0,000)$ dan sikap $(\mathrm{p}=0,000)$ pada kelompok eksperimen, sedangkan pada kelompok kontrol tidak ada perbedaan nilai pre-test dan post-test pada pengetahuan $(\mathrm{p}=0,649)$ dan sikap $(\mathrm{p}=0,532)$ di SMK N 1 Wadaslintang Wonosobo. (Wijoreni, 2014).

\section{KESIMPULAN}

Terdapat pengaruh senam diabetes dan gaya hidup (pola makan dan aktivitas) terhadap kadar gula darah. 
NERS: Jurnal Keperawatan,Volume 16, No. 1, Maret 2020, (Hal. 27-31)

\section{UCAPAN TERIMA KASIH}

Terima kasih kepada RISTEKDIKTI sebagai sumber dana penelitian dengan nomor kontrak 1444/E3/LT/2017.

\section{DAFTAR PUSTAKA}

American Diabetes Association. (2015). Diagnosing Diabetes and Learning About Prediabetes. In Www.Diabetes.Org/Diabetes-

Basics/Diagnosis. https://doi.org/1800-DIABETES (800-342-2383)

Erlina, L. (2010). Pengaruh Senam Diabetes Terhadap Kadar Glukosa Darah Pasien DM Tipe 2 Di RSU Unit Swadana Daerah Kabupaten Sumedang. Politeknik Kesehatan Bandung Jurusan Keperawatan, 1-8.

IDF. (2014). Idf Diabetes Atlas Sixth edition. Diabetes Atlas, Six Edi. https://doi.org/10.1016/j.diabres.2009. 10.007

Islaeli, B. N., Diarti, M. W., \& Jiwintoro, Y. A. (2019). Pemanfaatan Larutan Garam Natrium Klorida (Nacl) Sebagai Pengawet Alternatif Pada Urine Untuk Pemeriksaan Urine Metode Carik Celup. Jurnal Analis Medika Biosains (JAMBS), 6(1), 41. https://doi.org/10.32807/jambs.v6i1.1 23

Jiwantoro, Y. (2017). Riset Keperawatan (Analisis data menggunakan SPSS) (1st ed.). Mitra Wacana Media.

Liberty, I. A. (2016). Hubungan Obesitas dengan Kejadian Prediabetes pada Wanita Usia Produktif. Jurnal Kedokteran Dan Kesehatan, 3(2), 108-113.

Perkeni, P. B. (2006). Konsensus Pengelolaan Diabetes Melitus di Indonesia. Denpasar: PB. Perkeni, Dm, 1-26.

Shahab, A. (2009). Penatalaksanaan Dislipidemia Pada Diabetes Melitus

Lenny Rosbi Rimbun, dkk., Cegah diabetes melitus tipe 2....
Tipe 2,. Fakultas Kedokteran Unsri.

Sutrisno, M. (2008). Hubungan Tingkat Pengetahuan Pasien Dengan Kepatuhan Diet Pada Penderita Diabetes Mellitus Tipe 2.

Waspadji. (2009). Diabetes Melitus Mekanisme Dasar dan Pengelolaannya yang Rasional. Balai Penerbit FKUI.

Wijoreni, N. astuti. (2014). Pengaruh Pendidikan Kesehatan Tentang Gaya Hidup Sehat Terhadap Tingkat Pengetahuan Dan Sikap Dalam Mencegah Penyakit Tidak Menular. Hal 140. 